\title{
Diacronie
}

Studi di Storia Contemporanea

$N^{\circ} 7,3 \mid 2011$

«Spagna Anno Zero»: la guerra come soluzione

\section{Intervista a Gerhard Hoffmann [video]}

\section{Matteo Tomasoni}

\section{(2) OpenEdition}

\section{Journals}

\section{Edizione digitale}

URL: http://journals.openedition.org/diacronie/3169

DOI: 10.4000/diacronie.3169

ISSN: 2038-0925

\section{Editore}

Association culturelle Diacronie

\section{Notizia bibliografica digitale}

Matteo Tomasoni, «Intervista a Gerhard Hoffmann [video] », Diacronie [Online], № 7, 3 | 2011,

documento 23, Messo online il 29 juillet 2011, consultato il 02 mai 2019. URL : http://

journals.openedition.org/diacronie/3169; DOI : 10.4000/diacronie.3169

Questo documento è stato generato automaticamente il 2 maggio 2019.

Creative Commons License 


\title{
Intervista a Gerhard Hoffmann [video]
}

\author{
Matteo Tomasoni
}

Gerhard Hoffmann (1917): iscritto alla Gioventù Comunista di Vienna, sua città natale, partecipò in prima persona ai difficili anni del governo Dollfuss, durante i quali le strade della capitale austriaca furono teatro di scontri tra i sostenitori della Sinistra e i seguaci dell'austrofascismo e del movimento nazista. Nel 1938, poco prima dell'Anschlu $\beta$, fugge a Praga e da lì, nell'estate dello stesso anno, si sposta in Spagna, dove si arruola nelle Brigate Internazionali. Partecipa agli ultimi combattimenti della battaglia dell'Ebro e della difesa di Barcellona, per poi rifugiarsi in Francia nel gennaio del 1939. Conosce in prima persona le dure condizioni di vita degli esiliati nei campi di Saint Cyprien, Gurs, Argèles-sur-mer e altri ancora. Costantemente circondato da amici

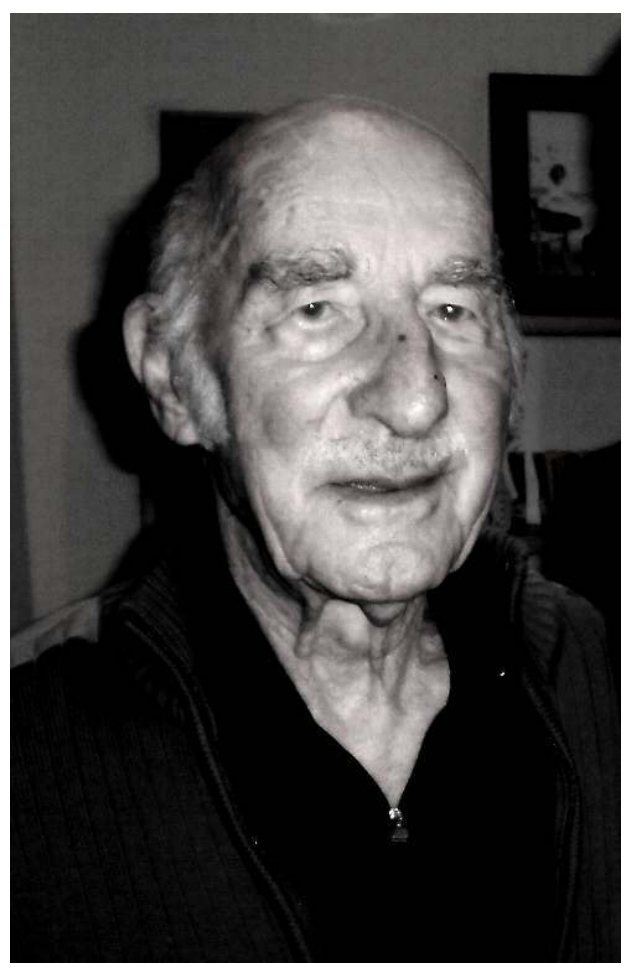
spagnoli, prende parte alla Resistenza e

lotta con loro per la liberazione della Francia. Segue gli alleati in Belgio e quindi in Germania (visitando le prima città tedesche occupate dopo i pesanti bombardamenti), per tornare nuovamente a Vienna verso la fine del 1945. Dopo aver assistito alle celebrazioni per la firma del Trattato di Stato e alla proclamazione della Seconda Repubblica Austriaca, si stabilisce definitivamente nella capitale, dove lavora e vive con la famiglia. In seguito partecipa a progetti di volontariato internazionale, soprattutto in 
Centroamerica (Nicaragua); attualmente, all'età di novantaquattro anni vive in un piccolo e tranquillo paese nei dintorni di Vienna.

Questo contenuto non può essere visualizzato in questa sede. Vi invitiamo a riferirvi all'edizione in linea. http://diacronie.revues.org/3169

Questo contenuto non può essere visualizzato in questa sede. Vi invitiamo a riferirvi all'edizione in linea. http://diacronie.revues.org/3169

\section{AUTORE}

MATTEO TOMASONI 